\title{
QUAL CONHECIMENTO MUSICAL QUEREMOS? UMA ANÁLISE DAS QUESTÕES ESPECÍFICAS DE MÚSICA DO ENADE 2009
}

\author{
Which musical knowledge do we want? \\ An analysis of 2009 Enade's specific music \\ questions
}

\author{
¿Cuál conocimiento musical buscamos? \\ Un análisis de las preguntas específicas de \\ música del Enade 2009
}

\author{
LEONARDO BORNE \\ Universidade Federal de Mato Grosso \\ leo@ufmt.br
}

\begin{abstract}
Resumo: Este trabalho tem como foco as questões específicas da área de música do Enade (Exame Nacional de Desempenho Estudantil) de 2009. As perguntas de partida são: como se organizam as perguntas do conteúdo específico no Enade para os cursos de música? Qual a sua relação com as Diretrizes Curriculares Nacionais (DCNs) específicas da área? A metodologia de trabalho adotada foi a pesquisa documental, buscando tendências no conteúdo das questões do Enade seguindo categorias emergidas das DCNs, a política de avaliação vigente, assim como os dados em si. Os resultados apontam que o Enade 2009 é um teste baseado no conhecimento do tipo memorizado e registrado de maneira verbal ou na partitura, o que não está de acordo com as próprias diretrizes em que se fundamenta a construção curricular que o Enade avalia, que se foca em competências. Por fim, as conclusões aqui chegadas pretendem fornecer subsídios para a reflexão e para o repensar a avaliação em larga escala em música.
\end{abstract}

Palavras-chave: Enade. Avaliação em música. Avaliação em larga escala.

\begin{abstract}
This paper focuses on the 2009 specific music questions of the Enade (National Exam of Students Performance), a Brazilian large-scale assessment that assesses undergraduate programs. The research questions are: how the specific music questions of the Enade are organized in the test? Which are the relationships between the test and the National Curricular Guidelines (DCNs) for Music undergraduate programs? A research protocol based on document analysis research was carried out. Results show that 2009 Enade is a test based on root-type of knowledge, and is registered verbally or with music sheet. The previous results do not agree with the guidelines that guide the music undergraduate program design, because they should be built on abilities and competencies. Lastly, conclusions intend to feedback ways to rethink music large scale assessment.
\end{abstract}

Keywords: Enade. Music assessment. Large scale assessment.

Resumen: Este estudio se enfoca en las preguntas específicas del área de música del Enade (Examen Nacional del Desempeño Estudiantil) del 2009. Las cuestiones de investigación son: ¿cómo son organizadas las preguntas las preguntas de contenido específico en el Enade para los cursos de música? ¿Cuál es su relación con las Directrices Curriculares Nacionales (DCNs) específicas del área? La metodología de trabajo adoptada fue la investigación documental, buscándose las tendencias en los contenidos de las preguntas del Enade, siguiendo las categorías surgidas desde las DCNs, desde la política evaluativa vigente, y desde los mismos datos. Los resultados apuntan que el Enade 2009 es una prueba basada en el conocimiento del tipo memorizado y registrado de modo verbal o en la partitura, lo que está en desacuerdo con las mismas directrices en las que se fundamenta el diseño curricular que el Enade evalúa, la cual se enfoca en competencias. Por ende, las conclusiones que aquí se llegan pretenden proporcionar insumos para la reflexión y para el replanteamiento de la evaluación en larga escala en música.

Palabras clave: Enade. Evaluación en música. Evaluación en larga escala. 


\section{PALAVRAS DE ABERTURA}

Como parte das políticas de avaliação nacionais, o Brasil possui a lei do Sistema Nacional de Avaliação da Educação Superior (Sinaes) (Brasil, 2004a), que funciona como uma sequência do antigo "Provão", 1 porém mais completa, envolvendo não só uma prova, mas um processo mais amplo que inclui a acreditação dos cursos - as avaliações in loco realizadas pelo Instituto Nacional de Estudos e Pesquisas Anísio Teixeira (Inep). Um dos pontos-chave do Sinaes foi a instituição do Exame Nacional de Desempenho Estudantil (Enade), que é uma prova em larga escala realizada anualmente incluindo diferentes áreas de conhecimento e suas respectivas graduações. Os resultados do Enade muitas vezes são utilizados para contrastar e comparar a realidade nacional com a internacional, além de se tornar uma ferramenta que gestores e políticos têm à disposição para emitir juízos de valor. Dessa forma, o Enade se torna um componente curricular obrigatório aos estudantes de graduação que tem como propósito gerar uma avaliação formativa dos currículos e cursos de graduação (Brasil, 2004a). Este trabalho tem, portanto, como temática central as questões específicas de música do Enade na sua edição de 2009 e sua relação com as normativas legais vigentes para formação de profissionais dessa área.

Um dos objetivos do Enade é gerar as informações sobre o desempenho dos estudantes para que as instituições de ensino superior (IES) possam monitorar e melhorar suas propostas curriculares; além disso, é um mecanismo de aferição de uma possivel qualidade dos cursos de graduação. O exame está organizado em ciclos de três anos, com a área da música no segundo ano desse ciclo; até o momento, a participação da área da música no Enade se deu nos anos de 2006, 2009 (bacharelados e licenciaturas), e 2011, 2014 e 2017 (apenas licenciaturas). Queiroz (2012), explica que a presença da música no Enade funciona como uma estratégia (até de cunho politico) que baliza a área e a coloca no mesmo patamar de importância das outras áreas no nível superior - o que, no futuro, pode gerar um efeito cascata para os outros niveis de ensino. Conforme diz o pesquisador, "essa premissa parte da constatação que qualquer área de conhecimento que almeje um espaço institucional legitimado precisa estar conectada com as diretrizes reguladoras e com os objetivos educacionais definidos por essas politicas" (Queiroz, 2012, p. 38).

Por outro ladro, uma questão que surge nos diálogos que tenho com docentes e especialistas da área e divide opiniões é a respeito da validade da participação de estudantes de música no Enade, dada que essa linguagem da arte é etérea e sem corpo concreto; somente sua notação escrita e as reflexões decorrentes do fenômeno sonoro são passíveis de serem registrados numa prova que tem como base a linguagem escrita. Em outras palavras, a música tem uma natureza prática que é alcançada através do fazer musical, fruto de um saber

\footnotetext{
1 "Provão" era o nome popular dado ao Exame Nacional de Conhecimento, instituído nos anos 1990 através da Lei no 9.131/1995 (Brasil, 1995). Dada a sua natureza de medição quantitativa sem promover insumos para mudanças curriculares e institucionais, ou seja, mudanças formativas, ele foi muito criticado e gerou muitos debates sobre a função da avaliação na educação superior. Quando se iniciou o governo Lula, esse debate deu origem, em 2004, à lei do Sinaes (Verhine; Dantas; Soares, 2006).
} 
musical que não é concreto e não consegue ser traduzido, em sua totalidade, com recursos gráficos. O que gera a divisão de opiniões é, precisamente, o fato de o exame do Enade ser construído com base na linguagem verbal escrita, o que não consegue explicar a música e limita a sua avaliação. Sobreira (2013, p. 9) argumenta que o perigo dos exames em larga escala como o Enade é que, por basear-se puramente no quantitativo, "não expressam necessariamente os conhecimentos adquiridos pelos estudantes. Dessa forma, ocorre a simplificação de um processo (avaliação) que é complexo e indispensável à ação escolar", o que se traduz na pedagogia do exame (Esteban, 2012 apud Sobreira, 2013) ou na cultura escolar ou cultura do exame (Borne, 2017; Salinas, 2002).

Paralelamente a isso, a área de educação musical carece de estudos sobre avaliação em larga escala, ao mesmo tempo que a literatura da área da avaliação carece de estudos sobre a música e a educação musical. Num recente estudo de Lima, Ambrosio, Ferreira e Brancher (2019, p. 89), que realizaram uma extensiva revisão sistemática da literatura sobre o Enade e o Enem, os autores concluíram que as "análises são limitadas, geralmente usando estatística descritiva, e focam, principalmente, em dados socioeconômicos e notas dos exames".

Ao consultar a literatura específica sobre o Enade, é possível encontrar publicações sobretudo nas áreas da saúde (Noro; Roncalli; Medeiros; Farias-Santos; Pinheiro, 2017; Santos; Afonso, 2017) e das ciências sociais aplicadas (Dias; Porto; Nunes, 2016; Feldmann; Souza, 2016). Na área da música, Queiroz (2012) e Sobreira (2013) falam de avaliação e políticas públicas, tocando no assunto do Enade tangencialmente, porém não se focam ou não abordam de forma sistemática o teor/conteúdo das provas, e como elas se relacionam com as propostas curriculares derivadas da legislação brasileira vigente sobre a construção curricular.

$\mathrm{Na}$ totalidade dos escritos consultados entre os temas abordados, destacam-se: as mudanças que o exame teve em relação ao seu pensamento inicial da política do Sinaes; o desempenho de estudantes e sua relação com a nota obtida no Enem; o enfoque de memorização da prova escrita em comparação ao caráter (inicialmente) formativo e por competências previsto no Sinaes; o uso das notas do Enade como elemento de marketing institucional, entre outros (Bittencourth; Viali; Casartelli; Rodrigues, 2008; Dias; Porto; Nunes, 2016; Feldmann; Souza, 2016; Rothen; Nasciutti, 2011; Sobreira, 2013; Verhine; Dantas; Soares, 2006).

Diante desse quadro, desenvolveu-se uma pesquisa que teve como propósito analisar as questões específicas de música nas cinco edições do Enade já mencionadas. As perguntas que guiaram a pesquisa foram: como se organizam as perguntas do conteúdo específico no Enade para os cursos de música? Qual a sua relação com as DCNs específicas da área de música?

Para viabilizar metodologicamente a pesquisa, a organização e análise dos dados foi dividida em cinco etapas, uma por cada edição do Enade. O presente trabalho se foca nos resultados que obtive com a prova aplicada em $2009 .^{2}$

2 Outros resultados já podem ser consultados, como a análise da prova de 2006 (Borne; Juvêncio, 2018 ), 2011 (Borne, 2020) e de 2017 (Borne; Hora; Silva, 2020). 
A meta ao ter as cinco análises concluídas é realizar uma comparação e contraste de todos os resultados obtidos e gerar elementos-guia de retroalimentação para a compreensão e construção de avaliações que efetivamente avaliem o estudante e o currículo, e não apenas meçam conhecimentos memorizados.

\section{DELIMITAÇÕES METODOLÓGICAS}

Para realizar este estudo, foram delimitadas algumas características que guiaram os percursos seguidos. Para começar, o olhar dado não se inclina definitivamente a uma abordagem qualitativa ou quantitativa, devido a que o que se propõe não é apenas responder o quanto ou o como, mas inter-relacioná-los, buscando criar sentido sobre as questões do Enade e sua vinculação com os documentos oficiais empregados em nivel nacional. Poder-se-ia dizer que é uma pesquisa mista, contemplando aspectos mais amplos que o qualitativo e o quantitativo (Peña Vera; Pirela Morillo, 2007). Como estratégia metodológica, esta pesquisa é concebida como uma análise documental que, segundo Sá-Silva, Almeida e Guindani (2009) é fundamentada em fontes primárias, ou seja, fontes que não receberam tratamento analítico ou científico prévio. Nesse caso, as fontes primárias são as provas do Enade (a seção de questões específicas da área de música), e, neste artigo, a prova de 2009.

Por outro lado, também segui as macrorregras propostas por Peña Vera e Pirela Morillo (2007) para a análise documental: a) omissão de informações com pouca importância; b) seleção dos elementos textuais relevantes; c) generalização propositiva de conceitos e de novas informações; d) a integração das informações, deduzindo, induzindo e gerando conceitos mais gerais e totais do discurso. Resumidamente, a análise desse conteúdo (questões do Enade) adota três conjuntos de ações: 1) reduzir os dados; 2) organizar e apresentar esses dados a partir das unidades que busca dar sentido entre eles; 3) elaborar conclusões e in(ter)ferências.

Os dados primordiais, que são as questões específicas de música do Enade, foram organizados em tabelas a partir de algumas unidades de análise (Sá-Silva; Almeida; Guindani, 2009) e, a partir destas, realizaram-se processos de análise de conteúdo e análises formais (Clausó García, 1993) através de uma perspectiva pragmática (Peña Vera; Pirela Morillo, 2007). O processo metodológico anterior significa buscar as relações entre texto e contexto, ou seja, entre o Enade e a legislação vigente. Para a análise, as questões foram organizadas e contrastadas com os eixos definidos nas Diretrizes Curriculares Nacionais para Cursos de Graduação (DCNs) de música (Brasil, 2004b, p. 2), que organiza o perfil profissional do músico a partir de três eixos. As DCNs dos cursos de música foram publicadas no ano de 2004 (Brasil, 2004b), e definem que as estruturas curriculares da graduação em música devem estar baseadas em nos eixos de conteúdos: básicos, específicos e teórico-práticos. A eleição de usá-las como parâmetro de organização e contraste no presente estudo se dá porque as questões específicas do Enade são elaboradas tendo como base as próprias DCNs. Ou seja, nada mais lógico analisar as questões do Enade, que finalmente avalia a proposta curricular das IES, com base no documento norteador para 
que as IES criem seus próprios currículos. Além disso, vinculei esses eixos a campos do saber musical em sub-eixos (pensados a partir de um estudo sobre currículos de graduação em música de Borne, 2017), conforme tabela abaixo:

Tabela 1: Eixos e sub-eixos da análise de dados.

\begin{tabular}{cc}
\hline Eixo & Sub-eixo \\
\hline A. Conteúdos Básicos & A1. Cultura, arte, filosofia, sociologia \\
& A3. Fundamentos da educação \\
\hline B1. Conhecimento geral de música \\
B2. Harmonia e contraponto \\
B. Conteúdos Específicos \\
B3. Lecto-escritura, percepção e teoria musical \\
B4. Análise e formas musicais \\
B5. História musical, etnomusicologia e musicologia \\
histórica \\
B6. Composição e improvisação \\
C1. Estágio e prática de ensino \\
C2. Performance musical \\
C3. Tecnologia e música \\
C4térico-Práticos
\end{tabular}

Fonte: DCNs para graduação em música (Brasil, 2004b) e dados da pesquisa articulados com o estudo de Borne (2017).

Ainda sobre o processo de organização dos dados, cabe salientar que eles foram organizados com o apoio de três músicos-pesquisadores do grupo de pesquisa MusA-UFC, que tiveram a função de juizes. Um juiz realizou a organização prévia dos dados de cada prova do Enade em tabelas do Excel, e estas foram revisadas pelos outros dois juízes que, em reunião do grupo, confirmavam ou redistribuíam os dados. Por fim, outros fatores também foram pensados na hora de organizar os dados. Nesse sentido, os seguintes aspectos foram verificados:

- o uso ou não de partitura ou outra notação musical nas perguntas e nas respostas;

- tipologia das perguntas (que são definidas pelo próprio Inep): asserção-razão, interpretação com resposta única, e múltipla resposta;

- caráter do item: lógico, de memorização ou reflexivo;

- contextualização musical ou social da pergunta;

- diferentes ênfases da graduação em música que teriam mais probabilidade de responder o item em questão. 


\section{ANÁLISE DOS DADOS}

Iniciarei as análises com a parte formal das perguntas, para depois passar a ver o conteúdo. O primeiro aspecto que trago são os modos de construção das perguntas, que são predefinidos pelo Inep em três categorias: asserção-razão (AR), interpretação com resposta única (IRU) e resposta múltipla (RM). Cada um desses itens demanda mais ou menos tempo de reflexão para responder a pergunta. Na totalidade das questões específicas de música, temos a seguinte distribuição: 19\% para asserção-razão; 22\% para interpretação com resposta única; e $29 \%$ para resposta múltipla.

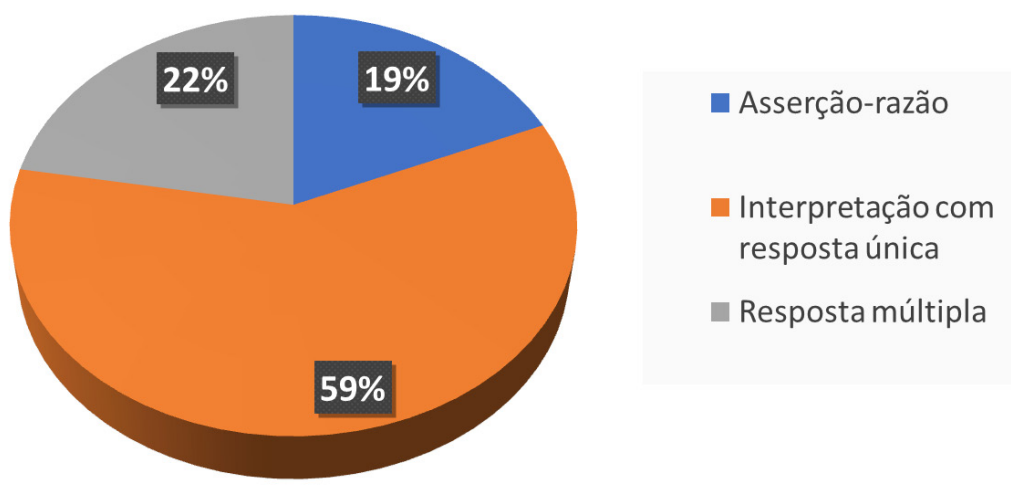

Figura 1: Tipos de pergunta. Fonte: dados da pesquisa.

Agora, vejamos alguns exemplos característicos dessa tipologia na prova de 2009: ${ }^{3}$

\section{QUESTÃO 14:}

Considere este trecho musical, da Fantasia KV 397, de Mozart:

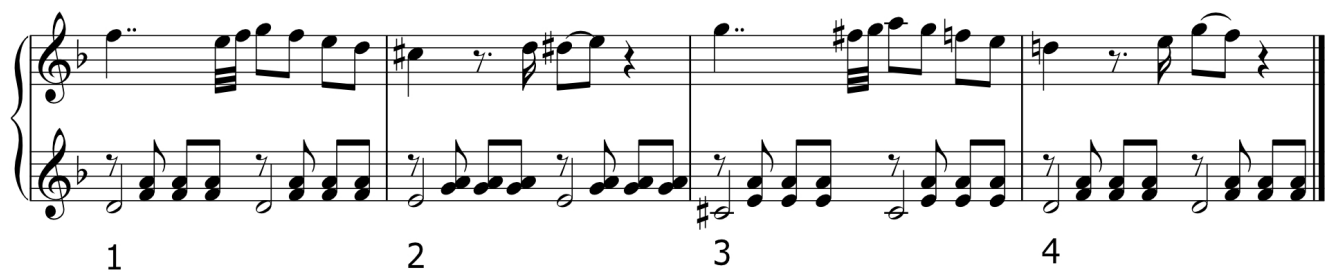

Os números indicados sob os compassos representam a progressão harmônica
A) I $-\mathrm{II}-\mathrm{V}_{3}^{4}-\mathrm{I}$
D) $i-v-v i i_{6}-i$
B) $\mathrm{i}-\mathrm{iv}-\mathrm{v}_{6}^{5}-\mathrm{i}$
E) $I_{6}-V-V-I_{6}$
C) $\mathrm{i}-\mathrm{V}_{3}^{4}-\mathrm{V}_{6}^{5}-\mathrm{i}$

(Tipo: interpretação com resposta única).

\footnotetext{
3 Para não repetir diversas vezes as fontes das questões ao longo do documento, optei por delimitar isso nesta nota. Todos os exemplos aqui listados foram retirados da prova de música do Enade de 2009, que pode ser acessada no site do Inep (Instituto Nacional de Estudos e Pesquisas Educacionais Anísio Teixeira, 2009).
} 


\section{QUESTÃO 19:}

A formação do educador musical, que valoriza os bens simbólicos e a identidade cultural dos grupos sociais nos quais ele atuará, tem origem no âmbito exclusivo das universidades.

\section{PORQUE}

As instituições de ensino superior cumprem o objetivo de desenvolver práticas que resultem no fortalecimento da identidade sociocultural dos grupos desassistidos socialmente.

\section{Considerando-se essas assertivas, é CORRETO afirmar que}
A) a primeira é falsa, e a segunda é verdadeira.
B) a primeira é verdadeira, e a segunda é falsa.
C) as duas são falsas.
D) as duas são verdadeiras, e a segunda justifica a primeira.
E) as duas são verdadeiras, e a segunda não justifica a primeira.

\section{QUESTÃO 25:}

Historicamente, os processos de ensino e de aprendizagem da performance instrumental e vocal baseiam-se na escrita musical, na criação musical, na oralidade ou na imitação.

Em relação a esses processos, considere as afirmativas seguintes:

I. A supervalorização do virtuosismo instrumental, no período Romântico, contrapõe-se à concepção de unidade vocal do Canto Gregoriano.

II. A pedagogia de cordas proposta por Shinichi Suzuki tornou-se conhecida por enfatizar a criação musical.

III. A pedagogia contemporânea do instrumento adota a leitura de partitura e o ensino dos conceitos teóricos nos estágios iniciais do aprendizado.

IV. A pedagogia do Bel canto aplica-se ao repertório vocal lírico, jazzístico e ao Sprechgesang (canto falado).

\section{É CORRETO somente o que se afirma em}
A) $\mathbf{I}$.
B) II.
C) III.
D) I e III.
E) II e IV.

(Tipo: asserção-razão)

A grande maioria das perguntas são do tipo IRU, que são perguntas mais diretas e que permitem correlações mais objetivas de maneira geral, como o exemplo da questão 14. Isso, inclusive, é abordado no curso de elaboradores de questões do Banco Nacional do Inep, com a indicativa de que as questões 
de IRU são mais rápidas de serem respondidas. Por outro lado, o excesso de perguntas tipo AR e RM pode inviabilizar a realização da prova completa na duração estipulada, dado o tempo que geralmente se usa para responder esses tipos de perguntas. Por essa razão, os coordenadores de cada área de elaboração de questões buscam fazer um equilíbrio nas tipologias das perguntas com intuito de não sobrecarregar os estudantes. ${ }^{4}$

Um segundo ponto que atentei na prova foi a presença de partitura nas perguntas ou nas respostas. Na edição de 2009, nenhuma prova tinha partitura nas respostas; no entanto, em 33\% das perguntas uma partitura era apresentada, e 67\% prescindia do seu uso.

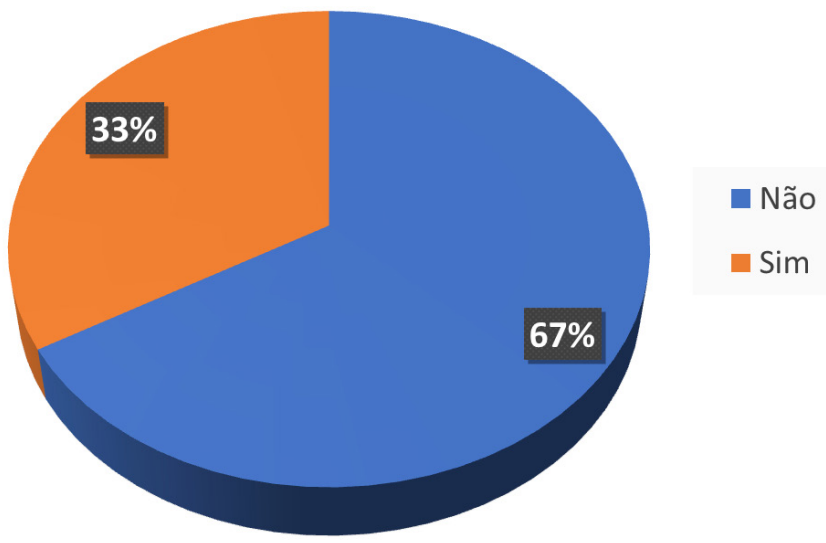

Figura 2: Presença de partitura na pergunta. Fonte: dados da pesquisa.

A partitura, apesar de polêmica nas discussões atuais da educação musical como um todo (como em Pereira, 2014), dado que geralmente é um fator vinculado a uma dominação e colonização do conhecimento (advindo da música ocidental europeia), é um dos poucos elementos concretos que a música possui, como comentado anteriormente sobre a questão etérea própria da linguagem. Por essa razão, especulo que a sua presença e uso numa prova massiva também sirva para demarcar o lugar e a especificidade do conhecimento musical frente às outras áreas. Além disso, o conhecimento da partitura, usualmente aprendido em matérias como linguagem ou teoria musical, pode revelar o nível de exigência de um determinado currículo sobre o domínio desse registro, além de ser um elemento importante no desenvolvimento de outras habilidades que envolvam a escrita musical, como a análise ou a harmonia musical (Borne, 2017). Dessa forma, a partitura na pergunta (como observado na questão 14 acima ou na 34 abaixo) na prova do Enade de 2009 geralmente faz referência a um conteúdo do eixo B (Conteúdos Específicos), que é a maioria nessa edição - como será tratado mais adiante.

\footnotetext{
4 Essa informação toma como base a minha experiência como elaborador de questões do Enade desde 2014 e os diálogos com outros elaboradores desde então. No entanto, por haver assinado um termo de confidencialidade, não posso (e não podemos) referenciar algum documento publicado pelo Inep.
} 


\section{QUESTÃO 34:}

Considere estes três trechos de obras musicais:
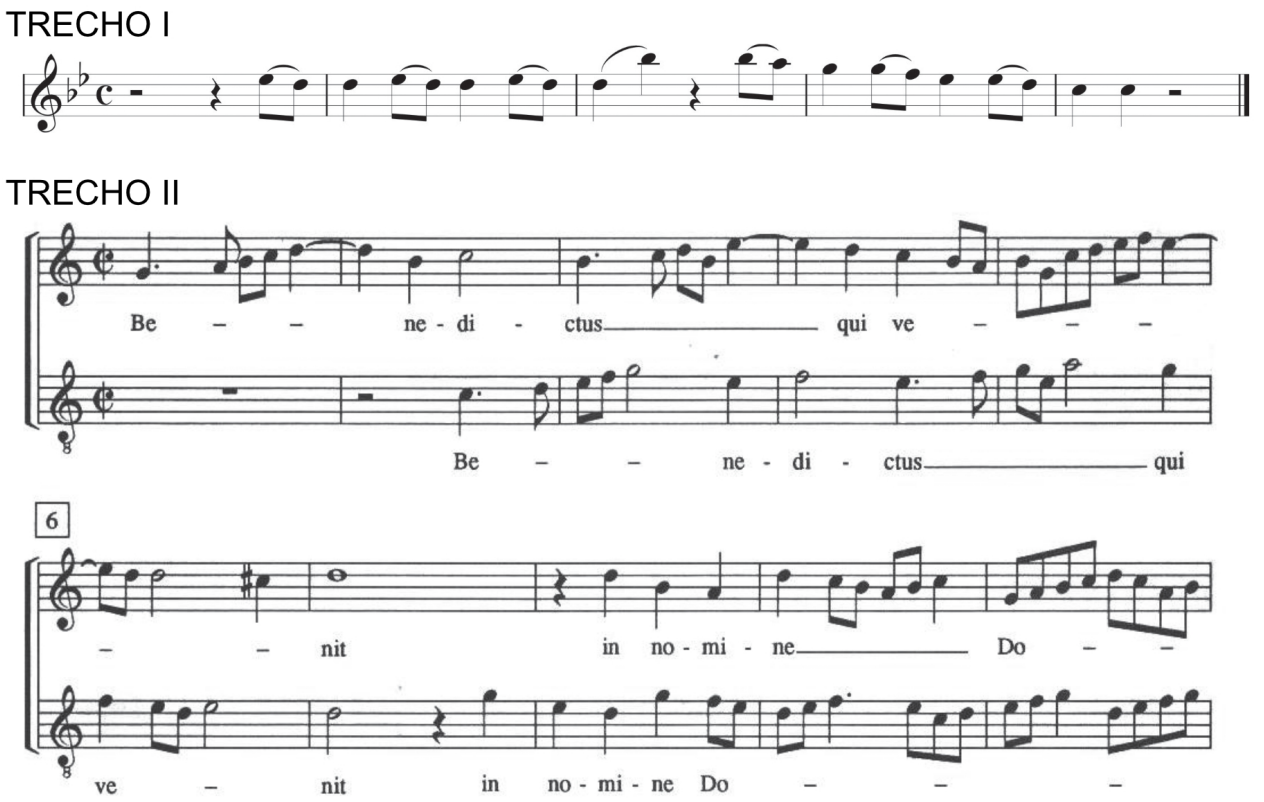

TRECHO III

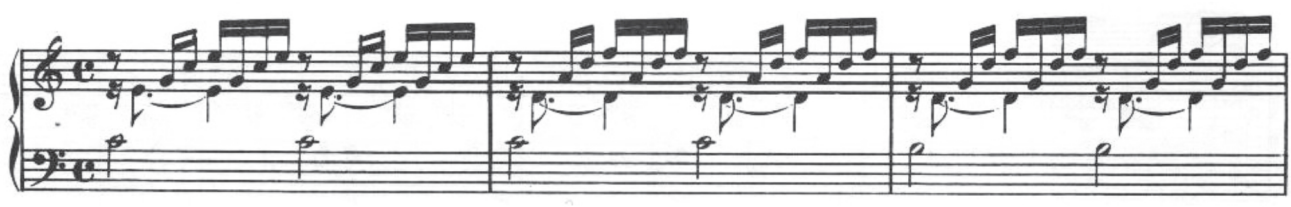

Com base nesses trechos, é CORRETO afirmar que essas obras pertencem, respectivamente, aos períodos
A) Barroco, Renascentista e Romântico.
B) Clássico, Barroco e Romântico.
C) Clássico, Renascentista e Barroco.
D) Clássico, Romântico e Barroco.
E) Romântico, Clássico e Romântico.

Outro ponto importante foi definir a prevalência do caráter que assumem as perguntas. Foram estabelecido três tipos de caráter, inclusive interconectando-os, dado que uma mesma questão pode ter um caráter misto: a) analítico, com perguntas que incitavam a análise de um contexto musical ou social (como a questão 34 acima, que vincula obras aos seus contextos histórico-musicais); b) reflexivo, onde se apresentam situações sobre as quais o estudante deve refletir com base nas suas próprias experiências para responder a pergunta (questão 19); e c) de memorização, que foca em conhecimentos declarativos que são memorizados sobre a música, sem necessa- 
riamente passar por um processo analítico ou reflexivo (por exemplo, saber que a frequência da nota Lá central é de $440 \mathrm{~Hz}$, ou como os exemplos das questões 22 e 23 abaixo).

\section{QUESTÃO 22:}

Qual alternativa NÃO se aplica ao período romântico da música erudita europeia?

A) Estreita ligação entre a literatura poética e a música programática.

B) Liberdade de modulação e elaboração do cromatismo harmônico.

C) Lirismo exacerbado e individualismo emocional.

D) Rigor formal de características nacionalistas e homogeneidade timbrística na orquestração.

E) Virtuosismo técnico exaltado no repertório solista e nas cadências de concerto.

\section{QUESTÃO 23:}

A matéria-prima utilizada pelos DJs provém de recursos eletroacústicos. Qual alternativa indica técnicas de criação musical utilizadas em suas performances?

A) Aumentação, mixagem e colagem.

B) Colagem, enarmonia e mixagem.

C) Mixagem, aumentação e scratch.

D) Mixagem, colagem e serialismo dodecafônico.

E) Scratch, mixagem e colagem.

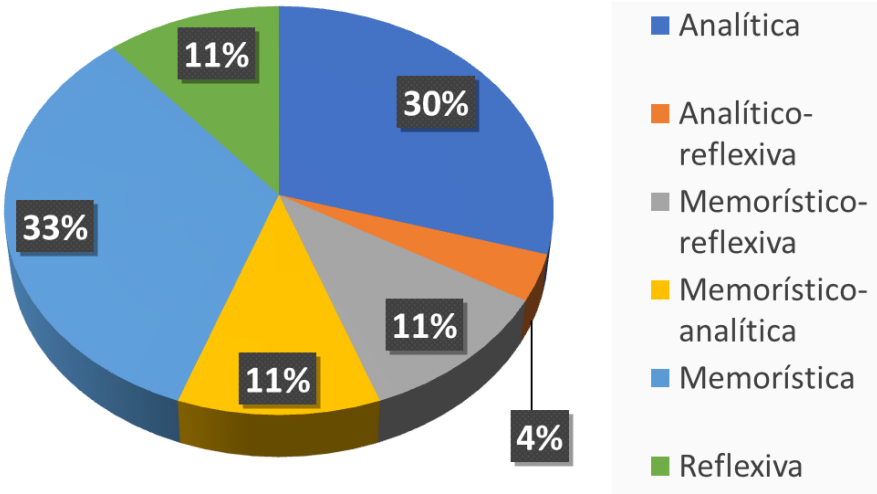

Figura 3: Caráter das perguntas. Fonte: dados da pesquisa.

Os dados mostram 33\% de perguntas de memorização, 30\% de tipo analítico, $11 \%$ de reflexivo, $11 \%$ de analítico-de memorização, $11 \%$ reflexivo-de memorização e 4\% de analítico-reflexivo. Como se pode notar, há uma prevalência em questões de natureza analitica ou de memorização (puras ou combinadas), perfazendo mais de 1/3 cada. É interessante notar que as perguntas do tipo reflexivo geralmente se vinculam a questões sociais da música, sua transmissão ou ensino, particularmente oriundos dos campos da educação musical e da etnomusicologia (como as questões 19 ou 24). Já os conhecimentos mais vinculados à linguagem musical e aspectos históricos 
da música erudita são construídas com questões analíticas ou de memorização (questões 14 ou 34).

\section{QUESTÃO 24:}

Leia o trecho a seguir:

A música pode ser considerada uma
forma de resistência e superação do
instituído, entendendo-a como uma
questão social, que realiza juntamente
com a política um vínculo que questiona
os valores sociais e as significações dos
sujeitos.
HINKEL, J.; MAHEIRIE, K. RAP - Rimas afetivas da
periferia: reflexões na perspectiva sócio-histórica.
Psicologia \& Sociedade; 19, Edição Especial 2: 90-99,
2007.

Em relação a essa temática, é CORRETO afirmar que o movimento hip hop
I. surgiu no final dos anos 1970 nos EUA, e é composto majoritariamente por jovens pobres e negros.

II. privilegia a música em detrimento das artes plásticas, da dança e da crítica social.

III. estabelece conexões entre aspectos estético-musicais da música eletrônica e a cultura da periferia urbana.

IV. contempla, em suas letras, a desigualdade socioeconômica, a discriminação racial e a violência urbana.

V. incide sobre o cotidiano e a reconstrução da identidade de um grupo social marginalizado.

Adentrando o teor de cada pergunta, sigo para a sua vinculação com as DCNs, nos seus eixos e sub-eixos. Observemos os gráficos a seguir, onde vemos a distribuição quantitativa das perguntas segundo os eixos das DCNs (A - Conteúdos Básicos; B - Conteúdos Específicos; C - Conteúdos Teórico-Práticos):

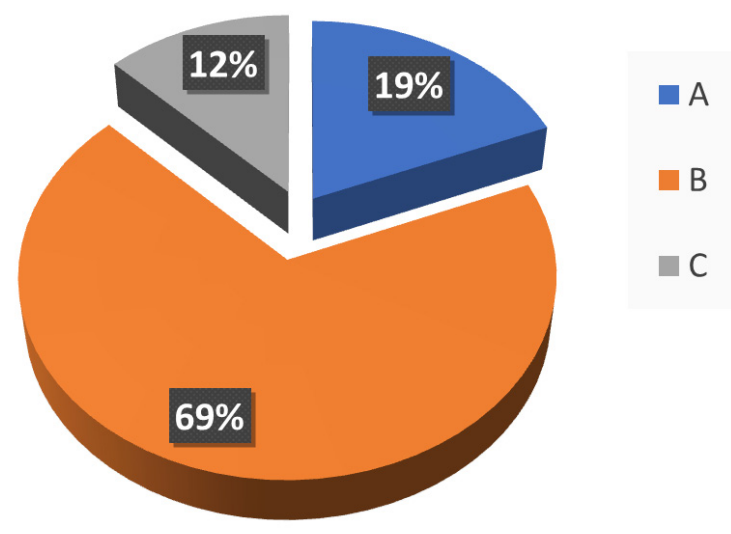

Figura 4: Relação eixos das DCNs-questões. Fonte: dados da pesquisa. 


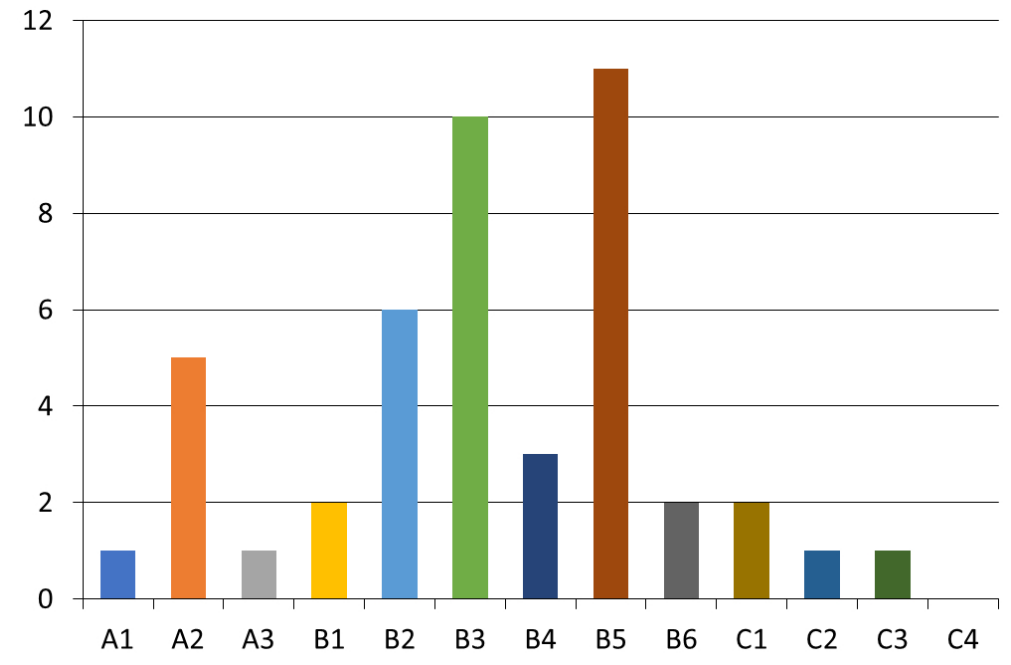

A1. Cultura, arte, filosofia, sociologia

A2. Educação musical

A3. Fundamentos da educação

B1. Conhecimento geral de música

B2. Harmonia e contraponto

B3. Lecto-escritura, percepção e teoria musical

B4. Análise e formas musicais

B5. História musical, etnomusicologia e musicologia histórica

B6. Composição e improvisação

C1. Estágio e prática de ensino

C2. Performance musical

C3. Tecnologia e música

C4. Pesquisa

Figura 5: Relação sub-eixos-questões. Fonte: dados da pesquisa.

Na Figura 4, vemos a distribuição de $12 \%$ de questões do eixo C - Conteúdos Teórico-Práticos, 19\% do eixo A - Conteúdos Básicos, e 69\% do eixo B - Conteúdos Específicos. A primeira informação que salta à vista é a massiva prevalência do eixo B, que se enfoca nos conhecimentos específicos de música: sua quantidade é superior à soma dos eixos A+C. Vendo mais detalhadamente, vemos que a maioria dos sub-eixos (A1, A3, B1, B4, B6, C1, C2, C3 e C4) tem pouquíssima frequência (entre 0 e 3), e apenas quatro desses sub-eixos (A2, B2, B3 e B5) concentram a maioria das questões. Importante destacar que B2 e B3 são parte de um corpus curricular muitas vezes chamado de linguagem musical, que possui grande carga horária em currículos de música (Borne, 2017; Pereira, 2014). O conceito de habitus conservatorial cunhado por Pereira (2014) parece fornecer pistas para explicação. Segundo o autor, há uma prevalência ou dominação de conteúdos geralmente atribuídos ao contexto do conservatório musical - que, como o nome diz, conserva a tradição musical e seu modelo de ensino, baseado na partitura, na prática exaustiva e nas aulas tutoriais -, o que pode estar em desacordo a determinados contextos musicais.

Por outro lado, a transversalidade curricular, ou até a interdisciplinaridade, que poderia ser trabalhada com questões que abordassem conhecimentos não declarativos ou mesmo nas questões de linguagem musical que perpassam mais de uma área, não figura na prova de 2009.

Somado a isso, os conhecimentos práticos (eixo C) quase não são avaliados no Enade, o que reforça a preocupação já levantada da dificuldade de avaliar um saber iminentemente prático e etéreo (ou sem corpo concreto) com uma prova textual. Vamos tomar como exemplo o sub-eixo C2, de performance musical. Num teste em larga escala que pudesse abarcar questões não 
verbais, seguramente se avaliaria a execução e interpretação musical através do fazer musical ao vivo ou gravado, utilizando rubricas ou baremas avaliativos predeterminados como os critérios avaliativos. No entanto, aí teríamos dois desafios: o logístico e o educacional. Logisticamente, como seria possível avaliar a interpretação musical de milhares de estudantes a cada três anos? Educacionalmente, como esses critérios avaliativos efetivamente representariam a diversidade musical do Brasil e, mais além, como os músicos estariam sendo preparados durante sua formação, seria unicamente para se sobressair no Enade ou seria para poder interpretar a música em toda sua completude? Essa complexidade dos diversos fatores pode ser extrapolada a outras áreas da música, como a própria parte auditiva da linguagem musical, a prática musicológica, as competências docentes e educacionais, etc.

Um último ponto sobre os sub-eixos que chama a atenção é que, no eixo A, há uma prevalência considerável de questões referentes ao campo da educação musical (A2). A educação musical, como área, é tida como multidisciplinar desde a sua origem (Kraemer, 2000). É interessante que, se não fosse pelas questões próprias da educação musical, o eixo B estaria ainda com mais predominância que os outros eixos, reforçando que o saber musical é um saber vinculado quase que exclusivamente à linguagem e à história da música.

Essa prevalência do sub-eixo A2 nos leva a quais ênfases de graduação em música teriam mais facilidade de responder a determinada pergunta, ou se todas as áreas de formação apresentariam a mesmas possibilidades. Por ênfase se entende aquela proposta curricular que direciona a formação do estudante desde o seu ingresso na graduação, o que é muito comum em música. Organizei os dados em seis possiveis ênfases: licenciatura, performance, composição, regência, etnomusicologia e musicologia. Cabe detalhar que não há graduação no Brasil nas áreas de etnomusicologia e musicologia, apenas oferta de pós-graduação; ainda assim, optou-se por deixar esses campos na análise, dado que alguns estudantes já se direcionam a eles na própria graduação e, consequentemente, surgem perguntas com temáticas acordes. Por outro lado, saliento que regência não teve nenhuma pergunta especificamente relacionada na prova de 2009, como mostra a Figura 6, e talvez isso se deva à natureza prática do fazer do regente. Ainda na Figura 6, vemos que 4\% são da área de composição, 7\% de musicologia e outros $7 \%$ de performance, $11 \%$ de etnomusicologia, $18 \%$ de licenciatura e 53\% das questões poderiam ser respondidas por pessoas de qualquer área.

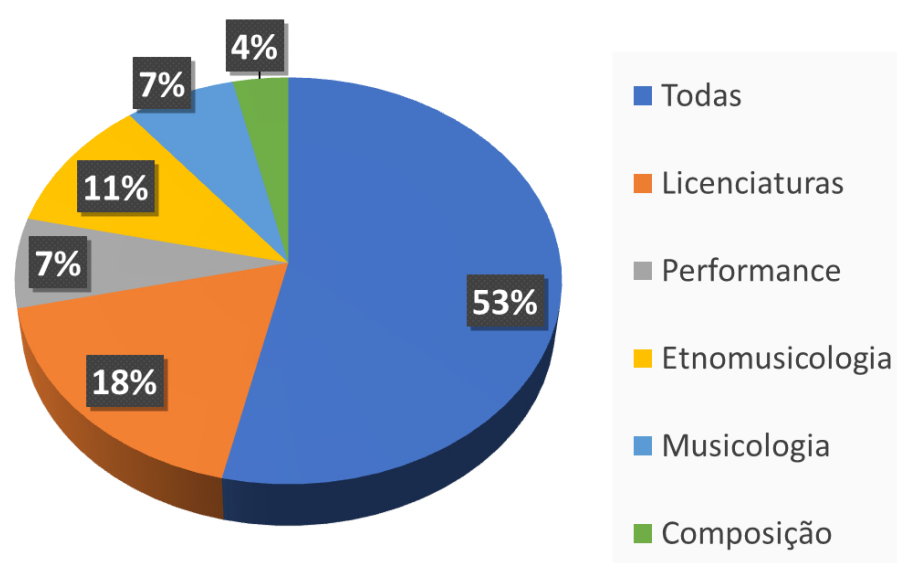

Figura 6: Ênfase. Fonte: dados da pesquisa. 
Um ponto ao mesmo tempo interessante e preocupante da prova de 2009 é o fato de que apenas pouco mais de $50 \%$ dela poderia ter sido respondida por um estudante de qualquer ênfase, já a outra metade se divide dentro das ênfases. É claro que um graduando de uma determinada ênfase pode possuir o conhecimento e responder algo de outra, porém isso não é a regra. Vejamos a questão 19 anterior: ela é própria do campo das licenciaturas (que, por sinal, prevaleceu em 18\% da prova), porém de que maneira os graduandos das outras ênfases poderiam possuir o conhecimento sobre as metodologias de ensino da música sem ter cursado os componentes curriculares específicos dessa ênfase e, então, responder à pergunta? Somente se eles tivessem realizado alguma formação externa. No entanto, essa formação externa não é o foco avaliativo do Enade, mas sim os conhecimentos adquiridos durante a formação inicial institucional e formal. O mesmo pode ser visto na questão 25 acima, com teor típico da licenciatura e da performance, ou na questão 16 abaixo, própria da ênfase composição musical.

\section{QUESTÃO 16:}

$\mathrm{O}$ advento das tecnologias digitais de composição musical permitiu o surgimento da música dodecafônica.

\section{PORQUE}

A divisão de uma oitava em doze sons da
escala cromática somente pode ser
realizada pelo computador.

\section{Considerando-se essas assertivas, é CORRETO afirmar que}
A) a primeira é falsa, e a segunda é verdadeira.
B) a primeira é verdadeira, e a segunda é falsa.
C) as duas são falsas.
D) as duas são verdadeiras, e a segunda justifica a primeira.
E) as duas são verdadeiras, e a segunda não justifica a primeira.

A análise anterior nos dá o vislumbre que a prova do Enade tem um grande desafio ao necessitar abarcar toda a diversidade do campo da música nas suas perguntas, ao mesmo tempo que contempla o conhecimento musical comum a todos. E essa diversidade pode fazer com que as questões se tornem enviesadas por não propiciar que todo e qualquer estudante as responda. Além dos casos acima mencionados com respeito às ênfases, nesta pesquisa também foi revisado o que chamei de contexto musical ou social específico, ou seja, perguntas com foco em algum aspecto que direcionassem e limitassem a sua resposta por todo o público no vasto território nacional que participa do Enade, gerando viés. Alguns exemplos já mostrados aqui são as questões 22, 23, 24, 25 e 34, todas relacionadas com um repertório ou um contexto social específico (DJs e hip-hop) que não são abordados em absolutamente todas as graduações em música. 
Dessa forma, como podemos ver no gráfico abaixo, há uma considerável quantidade de perguntas que se tornam enviesadas em um contexto musical específico, o que representa $1 / 3$ de toda a prova de 2009 . Isso, somado ao dito sobre as ênfases, sugere que a prova do Enade de 2009, no concernente aos conteúdos, não é uma ferramenta de avaliação que consiga abranger a diversidade de conhecimentos musicais que encontramos no Brasil e no mundo ocidental sem gerar injustiças ou prejuizos aos estudantes ou às suas instituições.

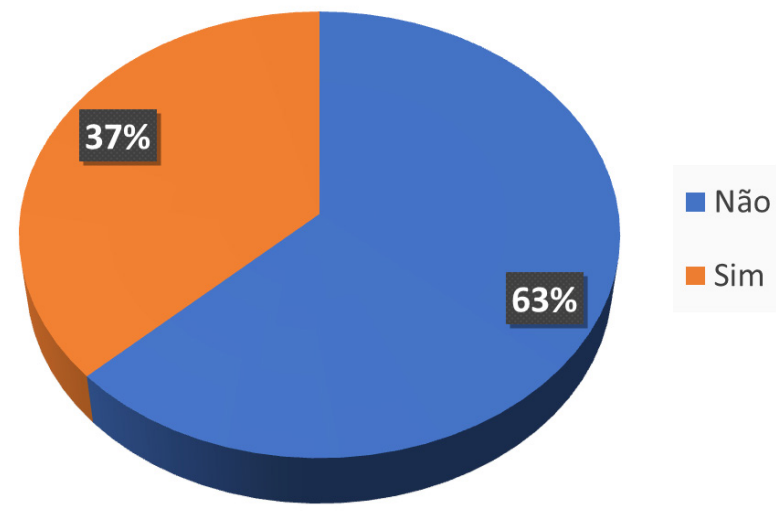

Figura 7: Viés (contexto musical ou social específico). Fonte: dados da pesquisa.

\section{ALGUMAS CONSIDERAÇÕES E PENSAMENTOS FINAIS}

O presente artigo se focou na análise das questões específicas da prova de música do Enade de 2009, com especial atenção na forma e no teor de suas perguntas. Partindo do pressuposto que os cursos são formulados com base nas DCNs, cabe pensar que a sua avaliação deve ser formulada sob as mesmas diretrizes, levando em consideração que se deve ter uma equidade sobre as bases que regem o documento, para assim aproximar-se de dados que representem a real formação.

Com base nos resultados obtidos, é possivel verificar que há questões que são dirigidas a uma ou outra ênfase específica dentro da música (como composição, licenciatura, performance, etnomusicologia, etc.) que não são, necessariamente, abordadas em todos os currículos de música. Isso pode gerar uma avaliação equivocada, não equitativa entre todos os currículos, e que não retroalimenta as propostas curriculares.

Além disso, não há distribuição totalmente equitativa das questões entre os três eixos definidos pelas DCNs e seus respectivos sub-eixos. Nota-se uma dramática prevalência de questões do eixo Conteúdos Específicos, e o eixo Conteúdos Teórico-Práticos segue com o menor número de questões; isso atribuo a uma dificuldade em medir teoricamente um conhecimento eminen- 
temente prático. Por outro lado, notamos que a noção de habitus conservatorial (Pereira, 2014) também norteia a criação de perguntas e gera distinções dentro dos conteúdos específicos. Também há um fluxo nos tipos de perguntas. Inicialmente, a maioria dos itens foi baseada em conhecimentos de memorização e analíticos, ainda que essa não seja a intenção declarada na politica do Sinaes (Brasil, 2004a), que preconiza o conhecimento por competências. Além disso, há uma correlação entre as perguntas do tipo de memorização com o eixo Conteúdos Específicos.

Outra situação vista foi o tipo de pergunta que, na sua massiva maioria, foi de interpretação com resposta única, talvez por escolha dos coordenadores de área da prova de música para não onerar o tempo de realização da prova. Escassos são os itens do tipo asserção-razão ou múltipla escolha, o que pode ser um fator que reforça o conhecimento de memorização e sugere que o discente seja tratado como objeto receptor de conteúdos.

Por fim, em todas as provas notei uma significativa quantidade de perguntas contextualizadas social ou musicalmente, especialmente quando trazem um repertório específico (por exemplo, um coco nordestino ou uma música de banda alemã sulista) ou são sobre um instrumento específico (por exemplo, uma peça do repertório romântico para piano). Nesses casos, não é possivel dizer que todas as formações em nivel superior trabalhem as mesmas obras musicais em todo o território nacional, e isso debilita a validade dessa avaliação massiva.

Com isso chego a uma constatação importante: os resultados e as considerações feitas falam de uma avaliação que, de fato, tende a medir conteúdos - tal qual o nome dos eixos das DCNs (Brasil, 2004b) - em lugar de habilidades e competências, o que é o foco da legislação do Sinaes (Brasil, 2004a). Igualmente, esses conteúdos geralmente são construídos com vieses culturais e sociais, que podem prejudicar a validade da avaliação. Com estas análises, tento chamar a atenção ao desafio que é avaliar o processo educacional em música, um campo do conhecimento repleto de vieses e construtos sociais e culturais, especialmente quando se trata de uma avaliação em larga escala.

Para concluir, temos que estar conscientes dos alcances e limites do esforço investigativo desta pesquisa, especialmente nas dimensões de uma análise mais profunda sobre o currículo e sua relação com as DCNs e com o Enade, o que posteriormente pode se concretizar na forma de estudos de caso. De maneira similar, a pesquisa também poderia se focar nas tradições acadêmicas e musicais entre as IES e as diferenças nos resultados do Enade. Tudo isso certamente daria mais dados para decisões mais informadas tanto ao Inep como às IES, ao mesmo tempo que proporcionaria mais luz sobre avaliação massiva em música, especialmente em nivel superior. 


\section{REFERENCIAS}

BITTENCOURTH, Helio; VIALI, Lorí; CASARTELLI, Alam; RODRIGUES, Alziro. Uma análise da relação entre os conceitos Enade e IDD. Estudos em Avaliação Educacional, [s. l.], v. 19, n. 40, p. 247-262, 2008.

BORNE, Leonardo. La evaluación del solfeo en contextos universitarios brasileños: un estudio multicaso. 2017. Tesis (Doctorado en Música) Facultad de Música, Universidad Nacional Autónoma de México, Ciudad de México, 2017. Disponivel em: http://132.248.9.195/ptd2017/ agosto/0763027/Index.html. Acesso em: 4 jul. 2018.

Enade 2011: uma análise das questões específicas de música. Ouvirouver, [s. l.], v. 16, n. 1 p. 306-327. 2020.

BORNE, Leonardo; HORA, Isabelle; SILVA, Dayvison. Large-scale assessment in Brazilian music higher education: a study of Enade 2017. In: BROPHY, Timothy; HANING, Marshall (ed.). Advancing music education through assessment: honoring culture, diversity, and practice. Chicago: GIA, 2020. p. 155-170.

BORNE, Leonardo; JUVENCIO, Francisco Ivan. Enade 2006: um estudo sobre as questões específicas de música. In: SEMINÁRIO NACIONAL SOBRE MÚSICA, CULTURA E EDUCAÇÃO, 2018, São Luís. Anais [...]. São Luís: UFMA, 2018. p. 90-99.

BRASIL. Lei $n^{\circ}$ 9.131, de 24 de novembro de 1995. Altera dispositivos da Lei $\mathrm{n}^{\circ}$ 4.024, de 20 de dezembro de 1961, e dá outras providências. Brasília: Presidência da República, 1995. Disponivel em: http://www.planalto.gov. br/ccivil_03/leis/19131.htm. Acesso em: 2 out. 2020.

Lei $n^{\circ} 10.861$, de 14 de abril de 2004. Institui o Sistema Nacional de Avaliação da Educação Superior - SINAES e dá outras providências. Brasília: Presidência da República, 2004a. Disponível em: https://www. planalto.gov.br/ccivil_03/_ato2004-2006/2004/lei/110.861.htm. Acesso em: 2 out. 2020.

Ministério da Educação. Conselho Nacional de Educação. Câmara de Educação Superior. Resolução n 2, de 8 de março de 2004. Aprova as Diretrizes Curriculares Nacionais do Curso de Graduação em Música e dá outras providências. Brasília: MEC/CNE/CES, 2004b. Disponível em: http://portal.mec.gov.br/cne/arquivos/pdf/CES02-04.pdf. Acesso em: 2 out. 2020.

CLAUSÓ GARCÍA, Adelina. Análisis Documental: el análisis formal. Revista General de Información y Documentación, [s. l.], v. 3, n. 1, p. 11-19, 1993. 
DIAS, Juliana; PORTO, Cristiane; NUNES, Andrea. Formação geral e conhecimento especifico na prova Enade. In: ENCONTRO INTERNACIONAL DE FORMAÇÃO DE PROFESSORES E FÓRUM PERMANENTE DE INOVAÇÃO EDUCACIONAL, 10., 2016, Farolândia. Anais [...]. Farolândia: Unit, 2016. p. 1-14.

FELDMANN, Taise; SOUZA, Osmar de. A governamentalidade e o Exame Nacional de Desempenho de Estudantes - ENADE. Avaliação: revista da Avaliação da Educação Superior, Campinas, v. 21, n. 3, p. 1017-1032, 2016.

INSTITUTO NACIONAL DE ESTUDOS E PESQUISAS EDUCACIONAIS ANÍSIO TEIXEIRA. Enade 2009: provas e gabaritos. Brasília, Inep, 2009. Disponivel em: http://enade2009.inep.gov.br/. Acesso em: 2 out. 2020.

KRAEMER, Rudolf-Dieter. Dimensões e funções do conhecimento pedagógico-musical. Em Pauta, Porto Alegre, v. 11, n. 16/17, p. 49-73, 2000 .

LIMA, Priscila da Silva Neves; AMBROSIO, Ana Paula Laboissière; FERREIRA, Deller James; BRANCHER, Jacques Duílio. Análise de dados do Enade e Enem. Avaliação: revista da Avaliação da Educação Superior, Campinas, v. 24, n. 1, 2019.

NORO, Luiz Roberto; RONCALLI, Angelo; MEDEIROS, Maria Cristina; FARIAS-SANTOS, Bárbara; PINHEIRO, Isabel. Relação entre conteúdos das disciplinas de curso de odontologia e os ENADE 2004/2010. Avaliação: revista da Avaliação da Educação Superior, Campinas, v. 22, n. 1, p. 125139, 2017.

PEÑA VERA, Tania; PIRELA MORILLO, Johann. La complejidad del análisis documental. Información, Cultura y Sociedad, [s. l.], n. 16, p. 55-81, 2007.

PEREIRA, Marcus Vinícius. Licenciatura em música e habitus conservatorial: analisando o currículo. Revista da Abem, Londrina, v. 22, n. 32, p. 90-103, 2014.

QUEIROZ, Luiz Ricardo. A Educação Musical no Brasil do Século XXI: articulações do ensino de música com as políticas brasileiras de avaliação educacional. Revista da Abem, Londrina, v. 20, n. 28, p. 35-46, 2012.

ROTHEN, José Carlos; NASCIUTTI, Fernanda. A educação superior em prova: o perfil da educação superior apresentado pelos resultados do ENADE 2005-2006. Revista Diálogo Educacional, Curitiba, v. 11, n. 32, p. 187-206, 2011.

SALINAS, Dino. ¡Mañana examen!: la evaluación: entre la teoría y la realidad. Barcelona: Grao, 2002. 
SANTOS, Nalbia; AFONSO, Luis. Análise do conteúdo das provas da área de Ciências Contábeis: edições do Provão 2002/2003 e do ENADE de 2006. Avaliação: revista da Avaliação da Educação Superior, Campinas, v. 21, n. 2, p. 387-413, 2016.

SÁ-SILVA, Jackson; ALMEIDA, Cristóvão; GUINDANI, Joel. Pesquisa documental: pistas teóricas e metodológicas. Revista Brasileira de História \& Ciências Sociais, Rio Grande, v. 1, p. 1-15, 2009.

SOBREIRA, Silvia. Abram alas que a música quer passar... nos exames: a avaliação como recurso para a aceitação do ensino de música nas escolas. In: REUNIÃO NACIONAL DA ANPED, 36., 2013, Goiânia. Anais [...]. Goiânia: $\mathrm{UFG}, 2013$. p. 1-13.

VERHINE, Robert; DANTAS, Lys; SOARES, José. Do Provão ao ENADE: uma análise comparativa dos exames nacionais utilizados no Ensino Superior Brasileiro. Ensaio: avaliação de políticas públicas em educação, Rio de Janeiro, v. 14, n. 52, p. 291-310, 2006. 
Leonardo Borne é educador musical, pesquisador e flautista. É graduado em Música e mestre em Educação pela Universidade Federal do Rio Grande do Sul (UFRGS), e doutor em Música - Educação Musical pela UNAM-México, além de possuir estudos em Musicoterapia pelas Faculdades EST. Atualmente é professor adjunto da Universidade Federal de Mato Grosso (UFMT), tendo passado pela UFC-Sobral, dedicando-se ao ensino, pesquisa e extensão nas áreas de educação musical, avaliação, teoria musical, percepção e solfejo, canto em grupo. Também se preocupa com os debates e a produção musical e educacional latino-americana. Sua produção científica tem sido apresentada e publicada em diversos contextos regionais, nacionais e internacionais, destacando-se o Fladem, a Isme, a Abem e a Anppom. http://orcid.org/0000-0002-8843-7017 